\title{
DESENVOLVIMENTO REGIONAL E LOCALIZAÇÃO INDUSTRIAL: UMA SISTEMATIZAÇÃO DAS TEORIAS CLÁSSICAS
}

Anderson Miguel Knob ${ }^{1}$ Ivan Colangelo Salomão

\begin{abstract}
Resumo: A centralidade que o campo do desenvolvimento regional alcançou nas últimas décadas ultrapassou o debate acadêmico para embasar políticas públicas de desenvolvimento local. O próprio fracasso de políticas de industrialização levadas a cabo no decorrer do século XX justificam a necessidade de se fazer avançar o conhecimento teórico e as práticas políticas de defesa do setor industrial nas economias periféricas. Nesse sentido, este trabalho procurou sistematizar as principais teorias clássicas de desenvolvimento regional e de localização industrial a fim de ensejar a interposição de novos elementos teóricos no debate contemporâneo.
\end{abstract}

Palavras-chave: Desenvolvimento regional. Localização industrial. Teorias clássicas. Política industrial. Desenvolvimento econômico.

\section{REGIONAL DEVELOPMENT AND INDUSTRIAL LOCATION: A SYSTEMATIZATION OF CLASSICAL THEORIES}

Abstract: The relevance that regional development has reached in the past few decades has surpassed the academic debate to support public policies of local development. The failure of industrialization policies adopted in the twentieth century justifies the importance to advance the theoretical knowledge and political practices of protection of the industrial sector in peripheral economies. This article summarizes the main classical theories of regional development and industrial localization in order propose the development of new theoretical elements in the contemporary debate.

Keywords: Regional development. Industrial location. Classical theories. Industrial policy. Economic development.

\section{DESARROLLO REGIONAL Y UBICACIÓN INDUSTRIAL: UNA SISTEMATIZACIÓN DE LAS TEORÍAS CLÁSICAS}

Resumen: La centralidad que el campo del desarrollo regional ha logrado en las últimas décadas ha ido más allá del debate académico para apoyar las políticas públicas para el desarrollo local. El fracaso de las políticas de industrialización llevadas a cabo durante el siglo XX justifica la necesidad de avanzar en el conocimiento teórico y las prácticas políticas de defensa del sector industrial en las economías periféricas. En este sentido, este trabajo buscó sistematizar las principales teorías clásicas del desarrollo regional y la ubicación industrial para dar lugar a la interposición de nuevos elementos teóricos en el debate contemporáneo.

Palabras clave: Desarrollo regional. Ubicación industrial. Teorías clásicas. Política industrial. Desarrollo económico

\footnotetext{
${ }^{1}$ Lucas do Rio Verde, Brasil, anderson_kn@agronomo.eng.br, https://orcid.org/0000-0002-7337-9301

2 Universidade Federal do Paraná (UFPR), Departamento de Economia, Curitiba, Brasil, ivansalomao@gmail.com,_https://orcid.org/0000-0001-5857-7505
} 


\section{Introdução}

O fenômeno do desenvolvimento econômico está intrinsecamente ligado aos fatores de produção de que se dispõe e a atributos ambientais exogenamente impostos. Conquanto relevantes, estes não são elementos necessariamente determinantes, uma vez que a interação com as características sociais de cada comunidade cria atmosferas específicas e irreproduzíveis, determinando diferentes ritmos de desenvolvimento socioeconômico para cada local analisado.

A temática sobre desenvolvimento regional faz-se presente desde, pelo menos, os fisiocratas, mas foi a partir dos clássicos que, sob influência da revolução científica e industrial, foram desenvolvidos os alicerces de diversas teorias posteriormente elaboradas - da escola keynesiana à neoclássica, passando pela abordagem do crescimento endógeno. Apesar de os principais marcos teóricos do desenvolvimento regional terem sido elaborados no século $\mathrm{XX}$, as bases desse campo de conhecimento remontam a obras publicadas há mais de um século.

Divide-se o arcabouço teórico do desenvolvimento regional em três correntes principais. As teorias clássicas de localização, desenvolvidas no início do século XIX, foi superada somente na década de 1940, quando a escassez de recursos monetários decorrente da Segunda Guerra Mundial e a eminente necessidade de reconstrução das economias europeias ensejaram a elaboração de novos marcos teóricos. Influenciada pelas ideias marshallianas de aglomeração e as intervencionistas de Keynes, o campo do desenvolvimento regional passou a abarcar elementos antes ignorados pelos neoclássicos, como as forças internas das concentrações urbanas, as relações entre os setores produtivos, os impactos de variáveis exógenas sobre 0 ambiente regional e as tendências de inércia das conjunturas econômicas internas. Após a sucumbência do sistema monetário internacional acordado em 1944, dos choques do petróleo (1973 e 1979) e da crise do sistema fordista, a década de 1980 assistiu à construção de novos modelos de desenvolvimento regional adaptados aos padrões de acumulação flexível, os quais, embasados nas mudanças dos regimes monetário, financeiro e produtivo, originaram as abordagens do desenvolvimento local endógeno. 


\section{Desenvolvimento regional no século $\mathrm{XX}$ : notas sobre o consenso contemporâneo}

As teorias de desenvolvimento regional ocuparam considerável destaque no cenário político e econômico mundial após a II Guerra. Foi a partir desse período que foram criados diversos órgãos governamentais aos quais se incumbia, dentre outros objetivos, a responsabilidade de formular políticas de desenvolvimento em suas respectivas áreas de atuação. No âmbito da Organização das Nações Unidas, por exemplo, surgiram as comissões dedicadas à Europa (CEPE), África (CEPA), América Latina (CEPAL) e para a Ásia e Extremo Oriente (CEPAEO), além do PNUD, ECOSOC e outros programas voltados para a promoção do desenvolvimento em áreas periféricas. No Brasil, destacaram-se as superintendências regionais, como a SUDENE (1959), a SUDAM (1966) e a SUDESCO (1967).

Essas organizações passaram a elaborar políticas públicas voltadas à promoção das atividades econômicas em âmbito local. Dentre os principais programas preconizados, destacavam-se o protecionismo alfandegário para consolidar a indústria nacional por meio da substituição de importações, medidas de alocação dos recursos externos para romper ciclos de subdesenvolvimento e a integração setorial para intensificar os encadeamentos produtivos. Tais princípios podem ser encontrados, respectivamente, nos trabalhos de Perroux, Myrdal, Hirschman e North, os quais compartilhavam a concepção da primazia do setor industrial para o crescimento econômico e fortalecimento das aglomerações urbanas (CARDOSO, 1995).

Em comum, trata-se de autores cujos modelos de desenvolvimento industrial remontam, em graus variados, à obra de Marshall, vanguardista na observação das vantagens econômicas presentes exclusivamente nas aglomerações industriais e que, a despeito das limitações físicas do espaço geográfico, fazem da interação entre os agentes econômicos o motor do desenvolvimento local. De acordo com o autor, as empresas situadas em aglomerações possuem acesso a vantagens que não obteriam atuando isoladamente. Assim, otimizam seu processo produtivo ao desfrutarem de fatores endógenos ao ambiente regional, tais como redes de empresas com serviço especializado, custos de transação e de insumos reduzidos, facilidade no acesso à informação e pesquisas tecnológicas, entre outros.

As vantagens presentes nas aglomerações a que Marshall se refere partem de três fontes distintas, a saber, economias de escala, economias de escopo e externalidades positivas da própria concentração. Entre as últimas, o autor destaca 
três tidas como elementares, posteriormente designadas de "tríade marshalliana": disponibilidade de mão de obra qualificada, presença de prestadores de serviços ou matérias-primas específicas e os spoillovers, entendidos como transbordamentos de tecnologias e conhecimentos técnicos no ambiente regional ${ }^{3}$.

Para Fujita e Krugman (1995), a tríade marshalliana conduz o ambiente regional para a especialização das atividades econômicas em virtude de dois fatores principais: os altos custos para realocar a estrutura da planta industrial e o aumento proporcional das vantagens econômicas com o transcorrer do tempo. Nesse sentido, Carlos (2001) aponta que as externalidades das aglomerações tendem a potencializar a concentração, pois a proximidade dos agentes econômicos promove o desenvolvimento de empresas satélites, atração de investimentos externos, qualificação da mão de obra, intensificação no fluxo de informações e adequação da infraestrutura regional.

A partir da observação da concentração de firmas e departamentos do mesmo segmento, Porter (1999, p. 211) define o conceito de cluster como "um agrupamento geograficamente concentrado de empresas inter-relacionadas e instituições correlatas numa determinada área, vinculada por elementos comuns e complementares", cujo interesse não está na simples aglomeração de empresas concorrentes, mas no potencial dos vários componentes da cadeia produtiva maximizados pelo aumento no fluxo de informação, bens e serviços, com custos de transporte e tempo reduzidos.

Por outro lado, as aglomerações sofrem forças descentralizadoras que induzem ao deslocamento das empresas de regiões tradicionalmente industriais para as novas e sem tradição histórica na atividade. Esse deslocamento justifica-se pela busca de "externalidades" benéficas, como incentivos fiscais concedidos pela administração local, mão de obra com custo inferior e sindicatos menos organizados. Outro fator que justifica a fuga das grandes cidades são as "deseconomias de aglomeração", definidas por Santos (2003, p. 24) como as dificuldades presentes em grandes centros urbanos geradas pela concentração, como o congestionamento do trânsito, encarecimento dos terrenos e problemas sociais, como a violência.

De acordo com Benko (2002) as "deseconomias de aglomeração" são caracterizadas em duas situações distintas: (1) as de natureza econômica, "como a poluição e degradação do meio natural, a sobrecarga das redes de comunicação

${ }^{3}$ Diversos foram os autores que se utilizaram dessa tipologia das externalidades de produtores geograficamente concentrados para fazer avançar as teorias de desenvolvimento regional, com destaque para como Porter (1990), Krugman (1991), Markusen (1996) e Scott (1998). 
que provoca congestionamento nas metrópoles, a alta excessiva dos preços imobiliários e aumento do custo dos serviços públicos"; e (2) as sócio-políticas, "ligadas tanto às relações de trabalho, que tendem a evoluir para uma grande rigidez, envolvendo negociações coletivas de salários, regulamento do trabalho, pressões sindicais" quanto "às políticas urbanas, que podem aumentar os custos de produção pela modificação dos e pela imposição, criando 'clima' desfavorável aos negócios" (BENKO, 2002, p. 148).

Os benefícios decorrentes das atividades industriais induzem os governos municipais e estaduais a conceder incentivos fiscais e vantagens das mais diversas ordens com o propósito de atrair empresas motrizes. Dentre as principais medidas, destacam-se a redução ou isenção de determinados impostos, doação de terrenos, apoio em implantação de infraestrutura etc.; tais incentivos não garantem, porém, os retornos desejados, o que pode desencadear, por seu turno, as chamadas "guerras fiscais" entre as regiões (OLIVEIRA, 2003).

Coelho (1996) também observa que a implantação de atividades "estranhas" à realidade regional atrai grandes massas populacionais de outras regiões sem a devida preocupação de aporte às premissas básicas de bem-estar social, aumentando o número de pessoas submetidas à vulnerabilidade social. Como solução, o autor sugere que investimentos externos sejam direcionados com base nas potencialidades locais. Dessa forma, prioriza-se o desenvolvimento regional endógeno, no qual os benefícios desfrutados pelas empresas não são induzidos por políticas públicas forçadas; antes, partem de origens naturais da estrutura de mercado local, garantem sinergia à comunidade e sustentabilidade ao complexo produtivo.

A fim de fortalecer tais potencialidades locais, Porter (1986) elencou pontos fundamentais que devem ser construídos por políticas públicas, como a criação e fortalecimento de micro e pequenas empresas (MPEs) locais, melhoria da infraestrutura urbana, produtiva e social, incentivo à qualificação da mão de obra local, criação de serviços de apoio tecnológico, elaboração de novos tipos de relações empresariais, como cooperativas e empresas comunitárias e a promoção da imagem do município. Dessa forma, as administrações locais assumem também um caráter empreendedor no cenário econômico, e não apenas administrativo, tornando-se responsáveis por gerir parcerias, captar recursos e induzir novas oportunidades de desenvolvimento. 
Tais fatos estilizados apresentam em comum as origens teóricas, uma vez que foram desenvolvidos a partir do acúmulo de conhecimento gerado por autores vanguardistas da primeira metade do século $X X$.

\subsection{Os polos de crescimento de Perroux}

A teoria dos polos de crescimento foi desenvolvida pelo economista francês François Perroux (1903-1987) ao observar o processo de concentração industrial de países europeus, mais precisamente a França e Alemanha. A teoria de Perroux apresenta traços marcantes da influência de Schumpeter (1986), principalmente na importância concedida à inovação e evolução dos paradigmas tecnológicos. Em seu trabalho, Perroux dedica-se ao estudo das relações existentes entre o que denomina de "empresas motrizes" e "empresas movidas", e a interação das atividades produtivas dessas empresas com o espaço econômico regional. Além disso, Perroux também discorre sobre os axiomas básicos do desenvolvimento regional, suas premissas, especificidades e formas de polarização.

Ao analisar as desigualdades econômicas entre as nações, Perroux (1967) afirma que o crescimento econômico não apresenta padrão de comportamento homogêneo e generalizado, mas "manifesta-se em pontos ou polos de crescimento, com intensidades variáveis, expande-se por diversos canais e com efeitos finais variáveis sobre toda a economia" (PERROUX, 1967, p. 65). Para o autor, esses polos de crescimento resultam da interação entre agentes ativos e passivos, sendo os primeiros representados por indústrias motrizes e polos de atividades concentradas, e os agentes passivos, pelas indústrias movidas e regiões dependentes.

Para ser classificada como empresa motriz, faz-se necessário que cinco critérios básicos quanto à produção e magnitude na economia regional sejam atendidos: (1) crescer à taxa média superior da indústria nacional; (2) possuir várias ligações de insumo-produto por meio de compra e venda dos insumos, realizadas no ambiente regional; (3) apresentar-se como uma atividade inovadora, geralmente de grande dimensão e estrutura oligopolista; (4) possuir elevado poder de mercado, influenciando preços dos produtos, insumos e a taxa de crescimento das atividades satélites à ela ligadas; e (5) produzir para os mercados nacional e estrangeiro (SOUZA, 2007). 
Segundo Perroux (1975), a polarização impulsiona e propaga o desenvolvimento econômico de quatro modos distintos, a saber, por via técnica, econômica, psicológica e geográfica. A polarização técnica refere-se aos paradigmas tecnológicos e inovações inseridas no sistema produtivo regional por meio das empresas motrizes e movidas; a econômica ocorre por meio dos pagamentos concedidos às empresas satélites localizadas na região, salários e impostos municipais; a psicológica acontece por meio da atração de outros investidores em função das expectativas geradas pela sua inserção; e a polarização geográfica, por fim, resulta das transformações ocorridas no espaço urbano devido à presença da empresa motriz, as quais trarão benefícios para outros segmentos produtivos.

A contribuição das indústrias motrizes para a economia regional extrapola sua produção global absoluta, pois se deve considerar as inúmeras relações estabelecidas com as indústrias movidas, o estímulo à inovação das atividades produtivas e a satisfação de demandas da comunidade local. Além disso, a atividade industrial per se gera novas demandas em todos os setores econômicos: no primário, decorrente da necessidade por matérias-primas, no secundário, por meio de demandas de equipamentos e demais produtos industriais necessários ao processo produtivo, e no terciário, através da prestação de serviços, geralmente terceirizados (PERROUX, 1967).

$\mathrm{Na}$ implantação de determinada empresa motriz, faz-se indispensável o atendimento a um conjunto de premissas básicas para viabilizar o empreendimento. Dentre esses, há os congênitos ao ambiente regional, como a disponibilidade de matéria-prima, recursos naturais e fatores edafoclimáticos, e os induzidos, como infraestrutura e atração de força laboral.

Os investimentos para sua implantação advêm, geralmente, de recursos da própria empresa motriz em conjunto com linhas de financiamento público. $\mathrm{O}$ atendimento à demanda da força laboral ocorre por meio das contratações diretas e indiretas, sendo as primeiras realizadas pela empresa central e abrangendo 0 alto contingente populacional, não raro demandando alterações da infraestrutura municipal para abrigá-las. Já as contratações indiretas devem-se às empresas satélites, destinadas a executar determinadas etapas dentro do processo e que atendem as necessidades de força laboral através da contratação da população local e da geração de renda por meio de pagamento de salários. 
No entendimento de Perroux (1967), compete ao Estado a responsabilidade de promover suporte às empresas motrizes, seja financiando a pesquisa e a difusão de inovações, seja por meio da abertura de mercados:

O poder de disposição das grandes unidades no interior de uma nação não é completamente independente do poder público que, mesmo nos países liberais, estimula a investigação, ajuda a propagar as grandes inovações, participa na conquista dos mercados e [...] contribui poderosamente para a instauração de eixos de desenvolvimento, zonas de desenvolvimento e nos de tráfico (PERROUX, 1967, p. 213).

Para Perroux (1967), a introdução de novas atividades econômicas via empresa motriz é inquestionável indutor do crescimento econômico regional, uma vez que altera as estruturas de produção, expande o nível de emprego, fortalece a formação da classe média urbana e intensifica o fluxo de bens e serviços locais. Por outro lado, o estabelecimento de tais empresas em determinado espaço geográfico não assegura necessariamente o êxito do desenvolvimento regional e expansão da economia local, uma vez que se fazem condicionantes fatores regionais intrínsecos ao espaço capazes de promover ganhos de mercado e fomentar a produção de forma espontânea e natural, sem a necessidade de dispêndios públicos para que se mantenham na região.

Os conceitos de Perroux foram aplicados para nortear políticas públicas de desenvolvimento regional em diversas economias, galgando forte influência nas tomadas de decisões de planejamento regional, tanto em países em desenvolvimento quanto nos centrais. A aplicação de políticas sem o devido embasamento teórico e empírico, porém, resultou em intenso debate acadêmico a partir dos anos 1970, no qual a teoria de Perroux foi responsabilizada pelo insucesso na redução das desigualdades e por gastos em empreendimentos ociosos, conhecidos posteriormente como "catedrais no deserto" ou "elefantes brancos" (CRUZ, 2000). Em sua defesa, o autor alegou que o insucesso de tais experiências se devia a estratégias inadequadas adotadas pelos mais diversos governos e à valorização demasiada dos fatores exógenos para o crescimento regional. Alegouse, naquele momento, que não foi considerada a importância de elementos endógenos para que determinada localidade pudesse se viabilizar e instaurar novos empreendimentos bem-sucedidos no ambiente econômico regional. 


\subsection{A causação circular cumulativa de Myrdal}

A corrente teórica do desenvolvimento regional também foi significativamente influenciada pelos trabalhos do economista sueco Gunnar Myrdal (1898-1987). Integrante da Escola de Estocolmo, Myrdal (1960) se opôs ao liberalismo da teoria clássica e, coerente com sua filiação social-democrata, defendeu a intervenção do Estado na economia com o objetivo de corrigir as falhas de mercado que naturalmente resultam em concentração de renda e desigualdade social entre regiões.

Nessa área, seu trabalho mais conhecido foi Teoria da causação circular cumulativa (1960), na qual dividiu os países entre desenvolvidos - caracterizados pela alta renda per capita e índices sociais e de crescimento econômico satisfatório e contínuo -, e os subdesenvolvidos, cujas economias apresentam baixo crescimento, expressiva desigualdade de renda e graves disparidades sociais. Em sua concepção, tais discrepâncias tendem a aumentar ainda mais os contrastes entre as regiões, uma vez que as mais desenvolvidas se beneficiam pelos proventos oriundos de sua condição. Em contrapartida, as regiões subdesenvolvidas tendem a debilitar-se ainda mais, pois a inexistência de infraestrutura socioeconômica repele novos investimentos e limita a aplicação de recursos que visam à geração de renda, mantendo-as presas em um círculo vicioso de pobreza. Para romper esse ciclo, Myrdal (1960) se apropriou de elementos da teoria keynesiana ao defender a intervenção do Estado por meio de políticas públicas que criem condições mínimas de investimentos capazes de incentivar a demanda local. Para tanto, elaborou o modelo que viria a dar o nome de seu trabalho.

Inicialmente, deve-se identificar as causas do subdesenvolvimento e da pobreza na região, buscando-se compreender a interação de tais causas com fatores exógenos sobre a economia local. Em seguida, elabora-se a política pública mais adequada ao contexto, considerando os fatores econômicos, sociais e culturais daquela região. Se planejadas com rigor técnico e aplicadas com apoio político, o autor sustenta que as políticas públicas de fomento regional incentivam as atividades econômicas como um todo, aumentando o nível de emprego, o que, por consequência, amplia a renda da população e aumenta o consumo de bens e serviços locais. Essa expansão inicial da demanda estimula a abertura de novas empresas, que ofertam mais empregos, cujos salários pagos aos novos colaboradores são reintroduzidos na economia regional por meio do consumo de 
necessidades básicas, gerando novas demandas consequentemente (LIMA; SIMÕES, 2009).

Nesse sentido, uma das principais contribuições de Myrdal (1965) à temática diz respeito à tendência espontânea e involuntária de concentração regional dos mercados. Nos termos empregados pelo autor, "se as forças de mercado não fossem controladas por uma política intervencionista, a produção industrial, o comércio, os bancos, os seguros, a navegação", além de outras atividades, como "a ciência, a arte, a literatura, a educação e a cultura superior se concentrariam em determinadas localidades e regiões, deixando o resto do país de certo modo estagnado" (MYRDAL, 1965, p. 51).

Nesse processo, o autor afirma que as aglomerações econômicas geram duas forças distintas: os backwash effects ("efeitos regressivos") e os spreads effects ("efeitos propulsores"). O primeiro tende a aumentar as desigualdades já existentes na região através da atração de investimentos, fluxo de capitais, capital humano e ganhos de aglomeração para as localidades centrais em detrimentos das regiões periféricas. Já o segundo gera externalidades positivas sobre as áreas circunvizinhas às aglomerações. Isso ocorre, principalmente, por inseri-las no processo produtivo via fornecimento de matérias-primas e serviços, bem como no acesso a bens de consumo e tecnologias originadas nas localidades centrais.

Apesar de incluídas no processo produtivo, as áreas periféricas restringem-se basicamente à produção de bens primários, o que não demanda processos contínuos de modernização, além de criar poucos encadeamentos produtivos, tornando seu crescimento consideravelmente mais lento do que nas áreas desenvolvidas. Nestas, a matéria-prima é industrializada de forma intensiva, com utilização de tecnologia e mão de obra especializadas. Tais elementos presentes nos países desenvolvidos, argumenta o autor, é o que proporcionam rendimentos mais elevados, os quais serão reinvestidos, por sua vez, em novas tecnologias produtivas.

O Nordeste brasileiro é um exemplo citado por Myrdal de uma região afetada negativamente pelos impactos dos backwash effects ocorridos a partir da década de 1930 com o Processo de Substituição das Importações. Apesar de as políticas do PSI terem estimulado significativamente a evolução industrial do Brasil, a formação dos complexos industriais ocorreu de forma concentrada e desigual, alocados principalmente no estado de São Paulo e Sudeste (CANO, 1985). Tal fenômeno de crescimento econômico desencadeou a emigração de diversas regiões do país para 
o Sudeste, sobretudo a nordestina, a qual passou a sofrer ainda mais com a contração populacional.

Em contrapartida, esse processo também gerou consideráveis spread effects para o Nordeste. O desenvolvimento das indústrias de bens finais no Sul e Sudeste aumentou significativamente a demanda por bens intermediários, como petróleo e matérias-primas agrícolas, insumos encontrados na Bahia, por exemplo. Ao desenvolver tais cadeias para atender a demanda, o fluxo de capitais e das atividades econômicas relacionadas ao setor intensificaram-se, formando encadeamentos para outros segmentos e instaurando uma causação circular cumulativa de desenvolvimento.

\subsection{Os encadeamentos produtivos de Hirschman}

Albert Hirschman (1915-2012) publicou, em 1961, The Strategy of Economic Development, considerada à época um dos principais estudos acerca do fenômeno do desenvolvimento regional. Nele, o autor analisa as relações entre os diferentes setores da estrutura econômica, a propagação do crescimento intersetorial e a formação de encadeamentos produtivos entre os segmentos econômicos gerados pelas demandas e ofertas inerentes a cada atividade.

De acordo com Hirschman (1958), o desenvolvimento econômico é resultado de sucessivos desequilíbrios econômicos que geram oportunidades de ganho para os setores diretamente ligados à origem dessa instabilidade. Assim, ao usufruir de tais desequilíbrios, os setores beneficiados se expandem e geram demanda para os setores anteriores e oferta para os posteriores. O desequilibro é repassado, então, para a próxima cadeia, e conforme avança, mais indústrias usufruem do crescimento inicial, aumentando de forma significativa o fluxo de bens e serviços. Nesse sentido, Hirschman (1958, p. 36) aponta que "as desigualdades internacionais e interregionais de crescimento são condição inevitável e concomitante do próprio processo de crescimento".

Segundo o autor, esse tipo de crescimento surge inicialmente em setores líderes ou nas "indústrias-mestre", representadas por atividades econômicas com alto grau de encadeamento produtivo "para frente e para trás" - por meio da oferta do produto final e da demanda das matérias-primas. Para Hirschman (1961), a capacidade de induzir o desenvolvimento é proporcional ao número de encadeamentos produtivos gerados pela atividade, e são mais intensos quando direcionados "para trás" (backwards), ou seja, criadores de demanda de matérias- 
primas, característica comum em indústrias de bens intermediários e de consumo final.

Nesse sentido, Hirschman (1958) não condena as economias baseadas em exportações de produtos primários, mas as define como uma etapa prévia de acumulação de recursos posteriormente destinados à industrialização: "Os rendimentos decorrentes do processo da produção dos produtos primários e sua exportação poderão ser despendidos inicialmente em importações, porém, essas importações, tendo atingido um volume suficiente, [...] as quais poderiam eventualmente ser substituídas por indústrias domésticas." O autor define esse mecanismo como "efeito em cadeia do consumo" (consumption linkage). Por outro lado, "os efeitos em cadeia retroativos e prospectivos mais diretos podem ser subsumidos sob o nome de efeitos em cadeia da produção." (HIRSCHMAN, 1958, p. 39).

Assim, denota-se a influência de Keynes sobre a teoria de Hirschman quando este delega à intervenção do Estado a incumbência de criar as condições para alavancar o desenvolvimento econômico em países subdesenvolvidos. Principalmente quando fatores como capital financeiro, educação técnica, disponibilidade de crédito e infraestrutura são insuficientes, condição típica das economias atrasadas, uma vez que se trata de uma infraestrutura econômica que dificilmente surge de forma espontânea (HIRSCHMAN, 1961).

\subsection{A base exportadora de North}

Em Location theory and regional economic growth (1959), o economista norteamericano Douglass North argumenta que os países percorrem trajetórias diferentes para alcançar o crescimento econômico e desenvolvimento social. Assim, North contrapôs-se à Teoria de crescimento dos estágios lineares - também conhecido como modelo de Rostow -, pela qual se entende o fenômeno do desenvolvimento como resultado de uma sucessão de etapas necessárias, sendo que as fases iniciais exigem sacrifícios sociais para que seja possível uma arrancada, capaz de romper o círculo vicioso do subdesenvolvimento. North contesta esse entendimento ao observar que o processo de desenvolvimento dos países da Europa não se replicou nos EUA ou em outras economias de industrialização retardatária, não podendo auferir aura de teoria geral, portanto.

O conceito central do modelo de North fundamenta-se no crescimento econômico baseado nas receitas geradas pelas exportações do setor primário e na 
consequente propagação para os demais setores da economia. Daí a designação por ele dada à sua teoria como sendo de base exportadora. Por ela, o autor considera que as regiões podem ser providas de fatores locacionais específicos, capazes de otimizar a produção e potencializar os rendimentos de determinada atividade econômica. Desse modo, justificar-se-ia a produção de algum bem além da capacidade de consumo local com o objetivo de destinar o excedente ao atendimento das demandas externas.

Para North (1955), as receitas obtidas pelas exportações são reinvestidas na economia local para fomentar o processo produtivo exportador e atuam sobre os demais setores produtivos com efeito multiplicador. Isso ocorre devido ao repasse dos pagamentos às indústrias de apoio e fornecedores de matérias-primas, bem como ao investimento em upgrade do paradigma tecnológico, gerando demanda para as indústrias de bens de capital e modernizando as tecnologias nacionais de produção. Desse modo, North (1977) justifica as exportações como fonte de recursos para o desenvolvimento de outros setores:
À medida que as regiões cresciam em torno de uma base de exportação, desenvolviam-se as economias externas, o que melhorava a posição do custo competitivo de seus artigos de exportação. O desenvolvimento de organizações especializadas de comercialização, os melhoramentos no crédito e nos meios de transporte, uma força de trabalho treinada e indústrias complementares, foram orientados para a base de exportação (NORTH, 1977, p. 300).

A formação das indústrias de exportação justifica-se pela existência de demandas externas sólidas e estáveis, ainda que, de forma individual, a venda para o estrangeiro não seja suficiente para garantir a consolidação de tais atividades em determinado ambiente regional. Isso ocorre, porque a distribuição das unidades produtivas é orientada pela busca da localização ótima, permitindo às empresas os menores custos finais de produção e a maior rentabilidade quando comparada a exploração da mesma atividade em outras localidades geográficas. Dentre os principais fatores de atração, destacam-se matéria-prima abundante, recursos naturais disponíveis, infraestrutura logística para escoamento da produção, existência prévia de indústrias de apoio e vantagens de acesso ao mercado regional. Quando esses elementos se encontram presentes e harmonizados, origina-se um processo de expansão econômica regional, caracterizado principalmente pela formação de indústrias dedicadas à prestação de serviço e à oferta de insumos para 
atividade exportadora, bem como pelo aumento da população local e fortalecimento das indústrias residenciais já existentes.

O autor destaca que o progresso das atividades de exportação enseja, ainda, a formação de centros nodais de distribuição. Beneficiados por sua localidade geográfica, tais hubs permitem redução nos custos de comercialização física e especializam-se em transacionar a exportação de produtos finais e importação dos insumos necessários à produção. Nesse sentido, North (1959) argumenta que apesar de os setores industriais e de serviços apresentarem taxas absolutas mais elevadas de emprego e renda, deve-se ao setor primário a origem dos estímulos para o crescimento inicial. A inevitável redução na oferta de empregos deste setor decorre de sua modernização, a qual, por seu turno, acaba por criar oferta de novas vagas nos setores que a sucedem na cadeia produtiva.

Para comprovar e dimensionar os impactos das indústrias exportadoras sobre a economia regional e indicadores sociais, North (1955) utiliza-se de pelo menos três indicadores: (1) o multiplicador keynesiano, que quantifica o efeito das atividades exportadoras sobre o produto interno regional; (2) o quociente de localização (QL), responsável por avaliar o grau relativo de concentração das atividades exportadoras frente a outras regiões; e (3) o coeficiente de especialização, para determinar o grau de concentração de determinada atividade face a outras na própria economia regional. Para tornar possível tais aplicações, North divide as empresas em dois tipos, as atividades de básicas e não-básicas. As primeiras estão diretamente vinculadas às atividades de exportação, já as não-básicas dedicam-se à produção de bens e serviços para o mercado interno.

Além da evolução da infraestrutura logística local, o progresso das atividades exportadoras conduz ao amadurecimento das empresas básicas, aumenta o rendimento operacional dos trabalhadores e afeta positivamente as perspectivas de empreendedores e firmas sobre a economia regional. Entretanto, a simples presença concomitantes de tais elementos não garante a sustentabilidade do desenvolvimento econômico regional, uma vez que os setores secundário e terciário ancoram seu desempenho no das atividades exportadoras, podendo estagnar quando da ocorrência de crises no setor primário (NORTH, 1977, p. 305).

Diante de tais condicionantes, o autor considera duas premissas básicas para o desenvolvimento econômico sustentável: a dinamização das atividades econômicas e a descentralização da renda per capita regional. A primeira provê segurança à economia regional por torná-la independente de um único setor. Para 
alcançá-la, deve-se viabilizar um arranjo das escolhas de produtores e empreendedores locais sobre quais itens produzir, orientados pela busca daqueles que lhe proporcionem a maior rentabilidade possível. Dada a coexistência no mesmo ambiente, as melhores taxas de retorno encontram-se nos mesmos produtos, concentrando a produção primária e tornando o ambiente econômico regional estagnado. Já concentração de renda perfis de demanda não satisfeita pela economia local, como a aquisição de artigos de luxo pelas camadas econômicas mais favorecidas, limitando, assim, o acesso a itens de subsistência por parte da massa depauperada da sociedade local (NORTH, 1959).

Apesar de as atividades dedicadas à exportação equilibrarem o saldo da balança comercial e atraírem recursos para as economias regional e nacional, a sustentabilidade do sistema econômico não se fundamenta apenas na obtenção de divisas estrangeiras; antes, decorre da interação destas com os demais fatores e agentes econômicos regionais, da garantia dos elementos básicos de bem-estar social e de sua distribuição por todos os estratos sociais. Por tais motivos, a teoria da base exportadora recebeu objeções e críticas de diversos autores por desconsiderar inúmeras variáveis e fatores influentes no crescimento e desenvolvimento econômico regional, tais como: gastos governamentais, investimentos dos setores internos na economia, necessidades de importação e propensão a poupar, dentre outros.

Para Tiebout (1956), a teoria da base exportadora falha, por exemplo, ao tornar a delimitação da região arbitrária, delegando o êxito das exportações a elementos endógenos. Para o autor, North também ignora a possibilidade de que determinado arranjo de fatores concorresse para a redução das exportações, sem afetar o desenvolvimento regional. Assim, Tiebout procurou limitar a teoria da base exportadora apenas à capacidade de determinação da renda no curto prazo, mas não de viabilizar o desenvolvimento regional. A dependência de países externos e a insegurança de economias voltadas para exportação também são criticadas por Souza (2007). O autor considera que uma economia baseada nas exportações se torna vulnerável às oscilações conjunturais do mercado internacional. Além disso, a teoria da base exportadora minimizaria a importância das importações para o bemestar da população e a competitividade das indústrias nacionais. 


\section{Localização industrial: apontamentos teóricos}

O espaço geográfico no qual se localiza determinada atividade econômica influi diretamente sobre seu processo produtivo, taxas de lucro e viabilidade econômica. Tais impactos devem-se, por sua vez, a fatores presentes no ambiente regional capazes de otimizar as atividades operacionais e potencializar os retornos financeiros - custos de fretes, disponibilidade de recursos naturais, matérias-primas abundantes, vantagens econômicas do mercado regional e incentivos tributários. Dessa forma, as empresas direcionam-se em busca de tais localidades e, ao se estabelecerem no espaço regional, geram externalidades econômicas positivas à economia local e induzem o crescimento econômico.

O início das teorias clássicas de localização industrial remonta à publicação de $O$ Estado isolado, de Johann Von Thunen, em 1826. Foi no início do século XX, porém, que o estudo sistematizado do tema auferiu ares acadêmicos a partir do momento em que os trabalhos a esse respeito passaram a se encaixar nos cânones científicos. Nesse período, passou-se a incorporar análises geográficas urbanoregionais e considerar os fatores locacionais como determinantes no processo de crescimento econômico. Ainda assim, os impactos dos fatores aglomerativos sobre as regionalidades só viriam a ser abordados a partir da segunda metade do século $X X$, quando da consolidação das teorias de desenvolvimento regional (SOUZA, 2007).

A partir dos anos 1980, as questões referentes à localização das atividades econômicas retomaram destaque no debate econômico, fortalecidas pelo colapso do modelo fordista e pela estruturação do novo sistema de produção flexível. Nessa nova era, as empresas desconcentram seu processo produtivo para novas áreas geográficas e embasam seu padrão de acumulação na automação integrada flexível, abertura comercial e desregulamentação econômica, levando em consideração não apenas questões econômicas, mas também as relações sociais e tecnológicas entre as firmas (CAVALCANTE, 2004).

O sistema de produção flexível remodelou as estruturas produtiva e organizacional das empresas, induzindo os empreendimentos modernos a atomizar seus departamentos para diferentes regiões no intuito de desfrutar das vantagens locais demandadas por cada etapa da produção. Assim, cada departamento localiza-se no ponto ótimo de produção, os centros administrativos e unidades fabris high-tech situam-se nas aglomerações e as atividades de extração e produção próximas das fontes de matéria-prima (AGOSíN; TUSSIE, 1993). 
De acordo com Pacheco (1997), a estrutura gerencial dos grandes empreendimentos modernos é segmentada em cinco células: (1) Centros decisórioadministrativos; (2) Laboratórios e centros de pesquisa e desenvolvimento; (3) Unidades fabris; (4) Fontes de matéria-prima e energia; e (5) Centro de venda e distribuição.

Os centros decisórios encarregam-se da gestão e elaboração de diretrizes administrativas, locados em centros urbanos providos de estrutura rodo-aeroviária e telecomunicações avançadas. Os departamentos de P\&D concentram-se próximo de universidades, centros de pesquisas com aporte tecno-científico e profissionais de alta qualificação técnica. As unidades fabris são divididas em duas formas distintas de produção: as high-tech, com demandas semelhantes aos departamentos de pesquisa, e as low-tech, destinadas à produtividade em larga escala, que requerem mão de obra barata e insumos de produção em abundância. As fontes de matériaprima buscam locais com disponibilidade de recursos naturais, fontes energéticas e logística adequada para escoamento. Por fim, os centros de venda e distribuição, dedicados à destinação dos insumos de produção e produtos finais para os mercados consumidores, localizam-se nos arredores de grandes concentrações populacionais (PACHECO, 1997).

O deslocamento das empresas em busca das vantagens produtivas tem desencadeado um processo de desconcentração industrial nas áreas tradicionais. Concomitantemente, tem reconcentrado a produção em locais sem legado histórico na atividade, mas que provêm os elementos supracitados que permitem a maximização dos lucros. Essa tendência deve-se, em grande medida, à evolução dos paradigmas tecnológicos, responsáveis por transformar as empresas intensivas em mão de obra em intensivas em capital. Apesar de estimular o crescimento econômico local, essa migração das unidades fabris geralmente abrange atividades de produção em escala, mantendo os centros decisório-administrativos, laboratórios de pesquisa e unidades high-tech - atividades de salários mais elevados - nas aglomerações urbanas.

\subsection{O Estado isolado de Von Thunen}

A já citada obra de Von Thunen ( $O$ Estado isolado em sua relação com a agricultura e a economia nacional, de 1826) é considerada o marco fundante das teorias de localização, especialmente por inserir o espaço geográfico como fator determinante na atividade econômica. 
Nela, o autor propõe um modelo teórico que busca explicar a ocupação do espaço rural pelas atividades agropecuárias em função da distância do local de produção até os centros urbanos, retratado na Figura 1. O modelo é composto por anéis que indicam a viabilidade de cada atividade agrícola vis à vis à distância em relação às cidades, representadas no ponto central do esquema. Os anéis mais próximos indicam viabilidade para atividades com maior frequência de produção e perecibilidade, como horticultura, fruticultura e gado de leite. As atividades de produção sazonal e com possibilidade de formação de estoque se concentram mais distantes, como silvicultura, grãos e pecuária de corte (OLIVEIRA, 2003).

Figura 1 - Modelo da localização agrícola de Von Thunen (1826)

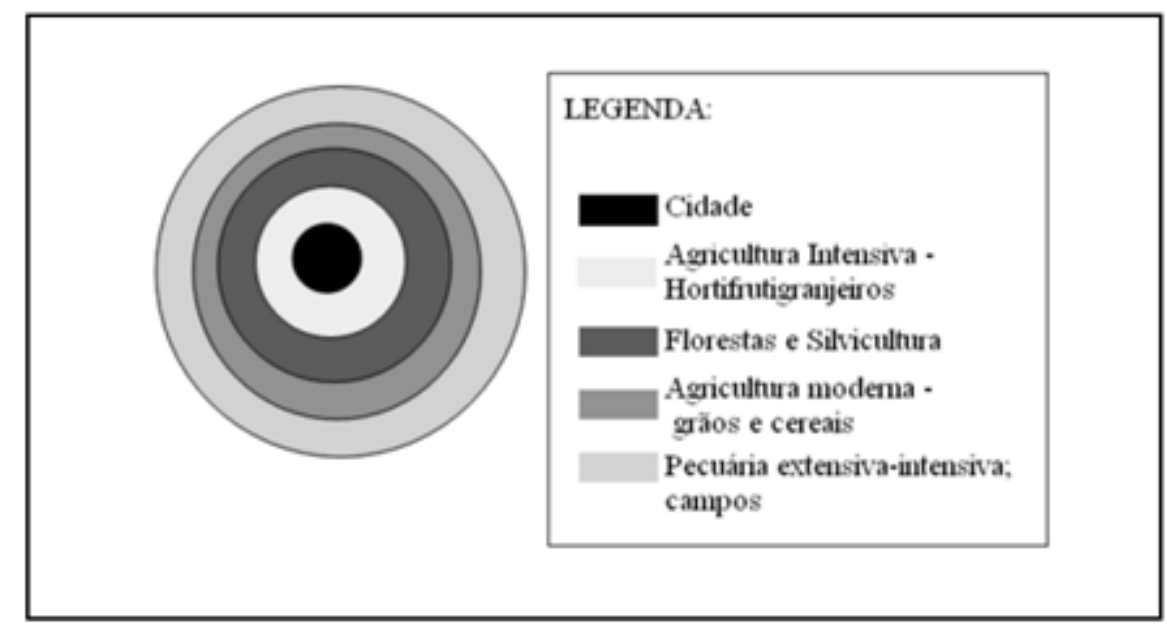

MONASTÉRIO; CAVALCANTE (2011).

Para explicar a ocupação espacial, Von Thunen considera apenas o fator da distância e características intrínsecas a cada produto, como perecibilidade e preço praticado na cidade, supondo as condições de relevo e fertilidade como uniformes. Consoante Mesquita (1978), o autor não concebe a variação dos fatores físicos, como, por exemplo, as condições da terra - se plana, arável e de fertilidade uniforme.

\subsection{A localização industrial de Weber}

Alfred Weber (1868-1958) defendeu em Teoria da localização industrial (1909) a primazia da localização ótima de produção como o fator determinante para o sucesso das firmas. $O$ autor dedicou-se a analisar os fatores básicos que estruturam a localização ideal das indústrias e elencou três elementos centrais: a distância dos insumos de produção e de centros consumidores, o custo de mão de obra e as forças aglomerativas internas. Assim, Weber destaca que as firmas devem 
analisar separadamente o impacto de cada um destes fatores para concentrar-se no ponto que permita os custos mínimos de produção (WEBER, 1929).

Segundo Clemente e Higachi (2000), o custo de produção de uma determinada indústria é afetado por fatores específicos - particulares a cada firma e fatores gerais, os quais, por sua vez, são subdivididos em regionais ou técnicolocacionais. Os primeiros correspondem às características da localização geográfica de forma ampla e determinam os custos de transporte e de produção, por exemplo. Já os fatores técnico-locacionais são o conjunto de elementos socioespaciais presentes em cada local específico dentro de uma região determinada, correspondendo, assim, aos ajustes finos da escolha locacional.

Para a validação de seu modelo teórico, Weber considera duas suposições obrigatórias: (1) as localizações das fontes de matérias-primas, assim como a posição e tamanho dos centros de consumo, são dadas e conhecidas; (2) e a mão de obra encontra-se em oferta ilimitada a uma taxa de salário determinada.

Para Weber (1929), a escolha da localização industrial depara-se com um paradoxo, visto que raramente as fontes de matéria-prima, centros consumidores, mão de obra e as forças aglomerativas encontram-se na mesma região. Assim, à medida que a firma busca se aproximar dos insumos, afasta-se dos centros consumidores e vice-versa. Esta relação de potencialidade inversamente proporcional obriga as empresas a encontrarem um ponto de equilíbrio entre os fatores, aproximando-se daqueles que representam os maiores custos de transporte.

A decisão de escolha da localização pode ser explicada, portanto, a partir do "triângulo locacional" (Figura 2), em que d1 e d2 representam a distância do local de produção até os insumos e d3, o centro consumidor. O modelo demonstra que a localização ideal não se concentra no mesmo espaço de um único insumo, mas pondera as distâncias a fim de otimizar os custos de transporte.

Figura 2 - Modelo do Triângulo Locacional de Weber

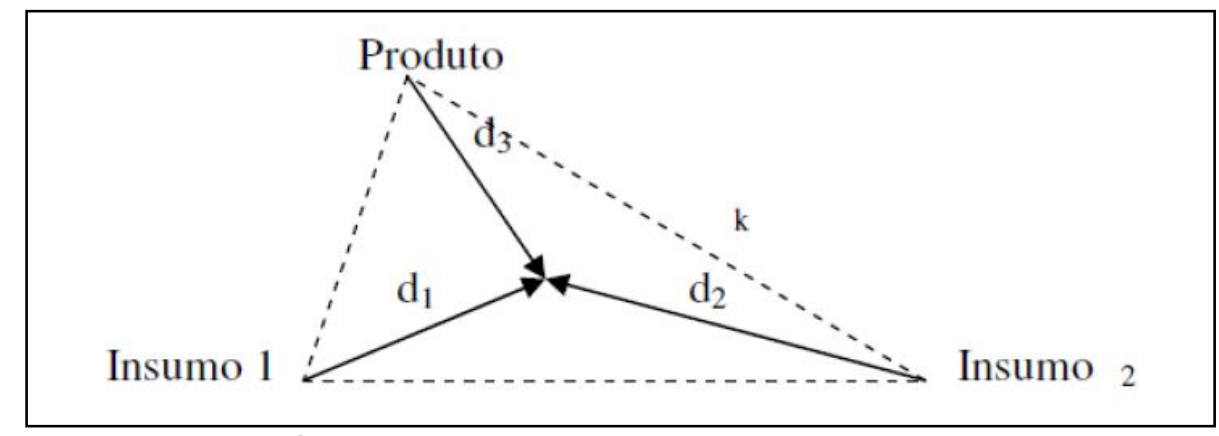

Fonte: MONASTÉRIO; CAVALCANTE (2011). 
No caso das agroindústrias, o produto final apresenta significativa diminuição de massa e volume após o processamento da matéria-prima. Assim, para este setor, a melhor localização é aquela próxima das matérias-primas, pois em função de seu peso maior, os custos de transporte tornam-se mais elevados.

\subsection{Os lugares centrais de Christaller}

A teoria de Walter Christaller analisa o espaço geográfico por meio de suas atividades econômicas e de sua relação com a organização populacional. O geógrafo apresenta um modelo embasado nas ideias de Von Thunen e Weber, transportado, contudo, para a realidade do espaço urbano e seu dinamismo característico. Christaller (1966) descreve o espaço geográfico como um sistema hierarquizado, ressaltando o fato de que a distribuição da população pode afetar o desenvolvimento das localidades centrais.

Para Christaller (1966), há uma relação diretamente proporcional entre desenvolvimento econômico e aglomeração demográfica, uma vez que o aumento populacional demanda maior fluxo de bens e serviços. Além disso, Christaller também observou que as áreas de mercado se moldam em formatos nos quais todos os espaços e consumidores são alcançados pela influência de alguma empresa. Para explicar a formação de tais áreas de influência, o autor propôs um modelo composto por regiões circulares, no qual se observou, porém, a existência de áreas que ficam descobertas entre as circunferências, demasiadamente pequenas para o surgimento de uma nova firma. Assim, concluiu que a influência de uma firma pode abranger distâncias maiores em alguma direção, as quais se expandem até o início da outra, formando uma estrutura hexagonal, tal qual uma “colmeia” (MONASTÉRIO; CAVALCANTE, 2011).

A dimensão das áreas de influência é formada por dois fatores principais: os custos de transporte e as características intrínsecas a cada produto, como a elasticidade-preço e frequência de consumo. Com custos de transporte menores, torna-se viável deslocar os insumos e produtos finais a uma distância maior; assim como produtos com elasticidade alta justificam a busca do consumidor por preços mais baixos, tornando os hexágonos maiores. As indústrias de produção em escala também tendem a aumentar o tamanho dos hexágonos, uma vez que a produção se concentra no espaço e necessita de grandes quantias de matéria-prima.

Ao observar as diferenças das áreas de mercado, Christaller considerou que as indústrias se dividem em processos produtivos de diferentes ordens. Ademais, 
ponderou a influência do produtor de ordem superior sobre os de ordem inferior, abrangendo parte de outros hexágonos além da integralidade da área que o cerca. Esse padrão de ocupação se justifica pela minimização do número de centros, do custo de transporte para os consumidores e das áreas que são compartilhadas por mais de um ofertante. Assim, a ocupação espacial se embasa em três princípios: o de mercado, o de transporte e o administrativo.

No princípio de mercado, que visa à minimização do número de centros, há uma influência visível do hexágono maior sobre o menor. Além de o produtor de ordem superior abranger a integralidade do mercado que compõem o seu hexágono, abarca também um terço da área mais próxima dos seis produtores que se localizam nos vértices de sua área. O princípio de transporte, que trata da minimização das distâncias entre os centros e consumidores, faz que os ofertantes de bens de ordem inferior se localizem na metade da linha que une os centros de ordem superior. Por esse princípio, a área de mercado dos centros superiores é quatro vezes maior do que a dos inferiores. Por fim, de acordo com princípio administrativo, objetiva-se a minimização da sobreposição dos centros de ordem superior sobre os de ordem inferior (CAPELLO, 2006).

Os três princípios estão descritos na Figura 3, na qual os pontos representam os centros urbanos, os hexágonos sua área de influência e a linha tracejada a relação igualdade entre eles. A dimensão dos pontos varia de acordo com seu grau de influência, sendo os maiores mais representativos na economia regional.

Figura 3 - Modelo de áreas de mercado dos três princípios de Christaller
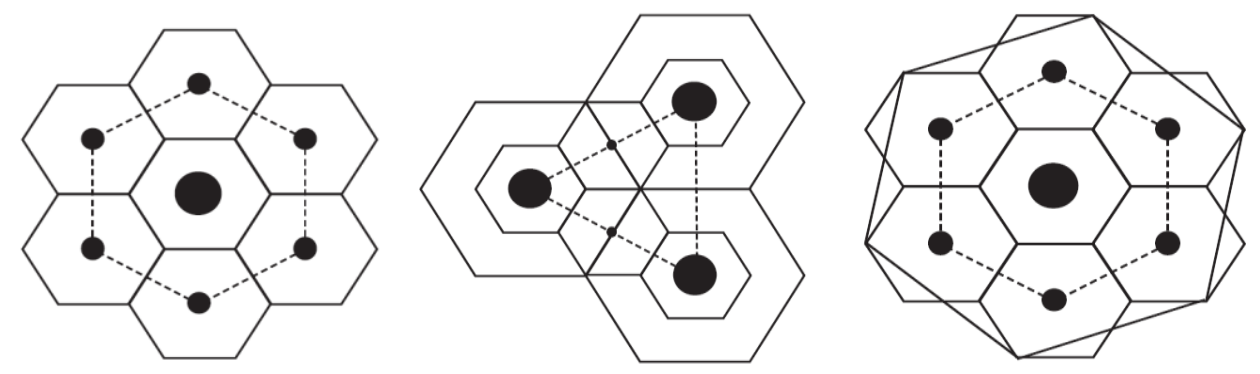

Fonte: MONASTÉRIO; CAVALCANTE (2011).

Nota: da esquerda para a direita, representam-se as áreas de mercado segundo os princípios de mercado, de transporte e o administrativo.

Apesar de a teoria proposta por Christaller (1966) apresentar algumas limitações, como a distribuição desuniforme da riqueza, as diferenças geomorfológicas dos espaços físicos e a imprevisibilidade da escolha do local de compra dos consumidores, o modelo mostrou-se útil e aplicável em determinadas 
políticas públicas. Desse modo, contribuiu para orientar a escolha da localização de centros e serviços de alta qualificação, como universidades, hospitais e centros de pesquisa. $\mathrm{Na}$ iniciativa privada, é aplicado no planejamento de rotas de transportes, escolha da localização de novos parques industriais e orienta as firmas na compreensão da geografia econômica regional (DUARTE, 1976).

\subsection{As áreas de mercado de Lösch}

Apoiado nos pressupostos de aglomeração desenvolvidos por Christaller, August Lösch ratificou a noção de que cada empresa abrange uma área de mercado. Para Lösch (1954), porém, as plantas produtivas podem se agrupar em um mesmo espaço físico, diminuir os custos de transporte e aumentar as externalidades positivas da aglomeração, mantendo seu mercado consumidor dentro de sua área de atuação. Os principais ganhos estão na distância e na produção em grande escala (ALVES; MAIA, 2009).

Na obra A ordem espacial da economia, publicada em 1940, Lösch foi o primeiro autor a relacionar em um único modelo a interação da demanda, preço final, distância e elasticidade de preços com a receita final das firmas. Na relação entre distância e preço final, o modelo corrobora o resultado a que chegaram Von Thunem e Christaller, qual seja, preço final crescente à medida que se aumenta a distância de deslocamento do produto. Ao relacionar este aumento dos preços com a quantidade demandada, a relação torna-se inversamente proporcional, reduzindo a demanda à medida que os preços sobem (BASTOS, 2007).

Para Lösch, a demanda máxima estaria no ponto de origem do produto, reduzindo conforme dele se afasta, devido, sobretudo, do aumento do custo final do produto, tornando-se nula a partir de um ponto extremo. A área formada entre a quantidade demandada e a distância máxima representa o total de vendas da empresa em unidades. Quando rotacionada, dá forma a um cone que corresponde à receita total da empresa (Figura 4). 
Figura 4 - Receita total da empresa

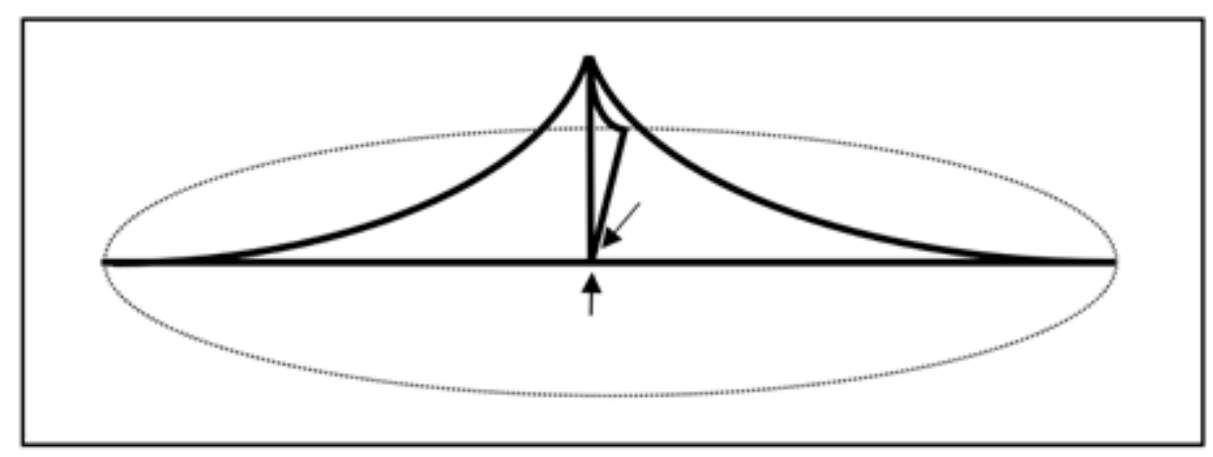

Fonte: Adaptado de MONASTÉRIO; CAVALCANTE (2011).

Para a validação de seu modelo, Lösch (1969) arrola as condições que devem ser satisfeitas no que toca aos espaços geográficos, o mercado e os consumidores e empresas:

1. Para o espaço: as distribuições espaciais das matérias-primas, do trabalho e do capital deve ser uniformes, assim como a infraestrutura e os custos de transporte devem ser proporcionais à distância percorrida.

2. Para o mercado: o mercado deve ser homogêneo, de concorrência monopolística e a demanda do produto deve ser dada pela acessibilidade e densidade da população. Essa demanda do produto criada pela população gera a demanda do transporte. Os custos de transportes também definem a área ótima de mercado. Caso ocorra um excedente de produção, criamse economias de escala as quais abrangem da área de mercado até o ponto máximo de custos de transporte.

3. Para as firmas e consumidores: Os consumidores devem se distribuir de forma uniforme, assim como suas preferências e seus rendimentos. Sua otimização de compra ocorre próximo ao ponto de origem do produto e se orientam pela utilidade dos produtos. Já para as firmas, consideram-se uniformes as tecnologias de produção e a estrutura de custos, além de serem orientadas pela maximização de lucros.

Tais premissas permitem que o modelo de Lösch possa ser adaptado a outras regiões sem prejudicar sua aplicabilidade ao reproduzir efeitos similares em diversas realidades. As "áreas de mercado" de Lösch assemelham-se à hierarquia urbana proposta por Christaller; por outro lado, diferenciam-se das demais teorias da localização ao inserir outras variáveis como fatores determinantes da localização 
ótima, além de destacar como fator de sucesso a busca pela maximização dos lucros, e não os custos mínimos de produção.

\subsection{A localização e economia espacial de Isard}

Walter Isard (1919-2010) exerceu um papel relevante entre os teóricos da localização, tornando-se o primeiro autor a desenvolver uma obra de relevância sobre a localização das atividades econômicas fora do idioma alemão, publicando, em 1956, a obra Location and Space Economy. Nela, Isard (1956) propõe a incorporação de modelos teórico-econômicos para analisar o espaço geográfico e as localizações industriais, instituindo uma linha de pensamento conhecida como "ciência regional". Seus estudos posteriores abordaram o comportamento econômico sob influência da variação espacial, principalmente aqueles relacionados aos custos de transporte, rendimentos crescentes e economia externa (KRUGMAN, 1991).

Apesar de considerar as principais teorias em sua análise, foi de Weber que Isard mais se aproximou, normatizando um modelo de minimização de custos no qual analisa a troca de elementos quando ocorrem variações de preços nos insumos. A aproximação com a teoria weberiana dá-se em função da forma como Isard (1956) classifica os fatores locacionais, considerando como fator central para a escolha locacional os custos de produção e transporte, os quais acabam por determinar a distribuição espacial das atividades econômicas (DONDA JÚNIOR, 2002).

Isard harmonizou as teorias de Von Thünen, Weber e Lösch ao contemplar os efeitos das variações espaciais sobre as atividades econômicas. Segundo Krugman (1998), os impactos observados no horizonte da economia espacial estão diretamente correlacionados à tendência do mercado em basear-se na concorrência perfeita durante as análises econômicas. Por esse motivo, faz-se necessário aproximar-se da concorrência imperfeita e rendimentos crescentes a fim de se aplicar uma análise empírica.

Logo que as obras de Isard começaram a ser traduzidas para outros idiomas, diversos autores passaram a perscrutar as novidades trazidas por seu modelo. A obra de Motta (1960), por exemplo, discorre sobre fatores de orientação industrial, caracterizada por estudos empíricos sobre teorias da localização a partir de diversos ambientes regionais no Brasil. Ancorado nos pressupostos de Isard, Motta (1960) define cinco fatores principais na orientação industrial: as matérias-primas, o 
mercado, a mão de obra, a energia para atividade produtiva ou outro fator específico para determinado empreendimento.

Apoiado na ciência regional desenvolvida por Isard, Krugman (1998) argumenta que as concentrações populacionais e as atividades econômicas baseadas no comércio são suficientes para explicar a distribuição das atividades agrícolas e industriais, sendo o deslocamento de um setor uma razão determinante sobre a localização do outro. $O$ autor acrescenta ainda que, em conjunto, esses segmentos promovem o desenvolvimento da economia regional e a integração entre os agrupamentos empresariais, impactando positivamente os indicadores socioeconômicos.

Essa integração entre os fatores históricos e físicos exige ações múltiplas dos agentes públicos por meio da utilização do conceito de ciência regional. As consequências do desenvolvimento regional e urbano são reflexo do cenário econômico, pois o ambiente econômico favorável subjaz a diretriz de concentração espacial e locacional (LIBERATO, 2008). Assim, a ciência regional de Walter Isard contribuiu consideravelmente para a formação de modelos teóricos de localização das firmas e métodos empíricos de análise espacial, incluindo a maioria dos modelos de input-output regionais empregados atualmente.

\section{Considerações Finais}

A proeminência que os estudos regionais vêm auferindo nas últimas décadas extrapolou o debate acadêmico para adentrar a seara das políticas públicas. As evidências empíricas de que a atuação do livre-mercado não contempla de forma satisfatória as necessidades dos povos de forma equilibrada evidenciou ainda mais a relevância dos estudos sobre desenvolvimento regional.

No caso das economias subdesenvolvidas, especialmente, a questão industrial granjeou destaque em função do antigo debate acerca da centralidade da indústria para se atingir o desenvolvimento pleno. Os países que se utilizaram do modelo de industrialização por substituição de importações demonstram a necessidade de se qualificar ainda mais o debate hodierno acerca dos mecanismos de desenvolvimento regional: diversas foram as economias que se industrializaram no decorrer do século XX sem, contudo, atingirem os níveis de desenvolvimento que se atingiu nos países centrais.

Nesse sentido, o resgate das teorias clássicas de desenvolvimento regional contribui para elucidar os itinerários percorridos por alguns países os quais, ao fim 
do processo, não lograram atingir o patamar de desenvolvimento inicialmente planejado. Conquanto não se tenha aplicado as recomendações teóricas tais quais elas foram elaboradas por diversos autores, o simples fracasso da maioria das estratégias adotadas por grande parte dos países da América Latina justifica o esforço de sistematização - quando não, de revisão - de parte significativa do conhecimento inicialmente gerado nas áreas do desenvolvimento regional e da localização industrial.

Intelectuais consagrados pensaram e propuseram modelos de desenvolvimento regional das mais diversos matizes. Dos liberais agrários aos intervencionistas pró-industrialização, as teorias de desenvolvimento regional contribuíram para embasar um debate caro não apenas no plano teórico, como principalmente, no da práxis humana. Nesse sentido, o avanço técnico e político que se observa na contemporaneidade remonta aos pensadores clássicos do tema, aos quais se tributam o arcabouço teórico de uma temática cada vez mais premente em um mundo de desigualdades crescentes.

\section{REFERÊNCIAS}

AGOSÍN, M.; TUSSIE, D. Globalización, regionalización y nuevos dilemas en la política de comercio exterior para el desarrollo. México: Fondo de Cultura Económica, 1993.

ALVES, F. D.; MAIA, A. C. Teorias sobre o espaço e a questão rural-urbano. In: FERREIRA, D. A. O.; FERRERA, E. F. (Orgs.). Estudos Agrários: Conceitos e Práticas. Rio Claro: IGCE, 2009.

BENKO, G. Economia, espaço e globalização na aurora do século XXI. 3. ed. São Paulo: Hucitec, 2002.

BASTOS, S. Q. A. Reflexões sobre o desenvolvimento local: a partir da análise do processo de industrialização de Juiz de Fora (MG). Juiz de Fora: UFJF, 2007.

CANO, W. Desequilíbrios regionais e Concentração industrial no Brasil, 1930-1970. São Paulo: Global, 1985.

CAPELLO, R. Regional economics. Londres: Routledge, 2006.

CARDOSO, F. H. Originalidade da cópia: a CEPAL e a ideia de desenvolvimento. In: CARDOSO, F. H. (Org.). As ideias e seu lugar: ensaios sobre as teorias do desenvolvimento. 2. ed. Petrópolis: Vozes, 1995.

CARLOS, A. F. A. Espaço-tempo na metrópole: a fragmentação da vida cotidiana. São Paulo: Editora Contexto, 2001.

CAVALCANTE, L. R. M. T. Produção teórica em economia regional: uma proposta de sistematização. Salvador: Universidade Federal da Bahia, 2004. 
CHRISTALLER, W. The central places of southern Germany. Englewood Cliffs: PrenticeHall, 1966.

CLEMENTE, A.; HIGACHI, H. Y. Economia e Desenvolvimento Regional. São Paulo: Atlas, 2000.

COELHO, F. D. Reestruturação econômica e as novas estratégias de desenvolvimento local. In: COELHO, F. D.; FONTES, Â. (Orgs.). Desenvolvimento econômico local: temas e abordagens. Rio de Janeiro: IBM, SERE/FES, 1996.

CRUZ, R. Marcos teóricos para a reflexão sobre as desigualdades regionais: uma breve revisão da literatura. Revista de Desenvolvimento Econômico (RDE), Salvador, ano 2, n. 3, p. 54-66, jan. 2000.

DONDA JÚNIOR, A. Fatores influentes no processo de escolha da localização agroindustrial no paraná: estudo de caso de uma agroindústria de aves. Dissertação (mestrado). Universidade Federal de Santa Catarina, Programa de Pós-Graduação em Engenharia de Produção, Florianópolis, 2002.

DUARTE, V. N. Desenvolvimento equilibrado versus desenvolvimento desequilibrado: uma breve revisão das principais teorias. Revista de Desenvolvimento Econômico, Salvador, v. 17, n. 31, p. 194-205, jan./jun. 1976.

FUJITA, M.; KRUGMAN, P. When is the economy monocentric? Von Thünen and Chamberlin unified. Regional Science and Urban Economics, v. 25, p. 505-528, 1995.

HIRSCHMAN, A. O. The strategy of economic development. New Haven: Yale University Press, 1958.

HIRSCHMAN, A. O. Estratégia do Desenvolvimento Econômico. Rio de Janeiro: Editora Fundo de Cultura S. A., 1961

ISARD, W. Location and space economy: a general theory relation to industrial location, market areas, land use trade and urban structure. Cambridge: MIT Press, 1956.

KRUGMAN, P. Increasing returns and economic geography. Journal of Political Economy, v. 99, p. 483-499, 1991.

KRUGMAN, P. Development, geography, and economic theory. 4. ed. Massachusetts: MIT Press, 1998.

LIBERATO, R. de C. Revisando os modelos e as teorias da análise regional. p.127-136. Caderno de Geografia. v.18, n.29. Belo Horizonte, 2008.

LIMA, A. C. C.; SIMÕES, R. F. Teorias do Desenvolvimento Regional e suas Implicações de Política Econômica no pós-guerra: o Caso do Brasil. Belo Horizonte: UFMG/CEDEPLAR, 2009.

LÖSCH, A. The economics of location. New Haven: Yale University Press, 1954.

LÖSCH, A. The nature of economic regions. In: FRIEDMANN J., ALLONSO, W. Regional development and planning: a reader. Cambridge, MIT, 1969.

MARKUSEN, A. Sticky places in slippery space: a typology of industrial districts. Economic geography, v. 72, n. 3, p. 293-313, July 1996. 
MESQUITA, O. V. O modelo de Von Thunen: uma discussão. Dissertação (Mestrado em Geografia). Rio de Janeiro: Universidade Federal do Rio de Janeiro, 1978.

MONASTERIO, L.; CAVALCANTE, L. R. M. T. Fundamentos do pensamento econômico regional. In: CRUZ et al. (Orgs.). Economia Regional e Urbana: teorias e métodos com ênfase no Brasil. Rio de Janeiro: IPEA, 2011.

MOTTA, F. O. Manual de localização industrial: uma tentativa de adequação da teoria à realidade. Recife: BNB/ETENE, 1960.

MYRDAL, G. Teoria econômica e regiões subdesenvolvidas. Belo Horizonte: Biblioteca Universitária/UFMG, 1960.

MYRDAL, G. Teoria Econômica e Regiões Subdesenvolvidas. Lisboa: Editora Saga, 1965.

NORTH, D. Location theory and regional economic growth. Journal of Political Economy, v. 63, n. 3, p. 243-58, 1955.

NORTH, D. Agriculture in regional economic growth. Journal of Farm Economics, v. 41, n. 5, p. 943-51, 1959.

NORTH, D. C. Teoria da Localização e Crescimento Econômico. In SCHWARTZMAN, J. Economia Regional: textos escolhidos. Belo Horizonte: Editora UFMG, p. 291-313, 1977.

OLIVEIRA, D. de P. R. de. Planejamento estratégico: conceitos, metodologias e práticas. São Paulo: Atlas, 2003.

PACHECO, R. Prerrogativas Locacionais face à economia globalizada: uma introdução conceitual. Fundação Konrad Adenauer Stiftung. Pesquisas n. 8, 1997.

PERROUX, F. A Economia do Século XX. Lisboa: Livraria Morais Editora, 1967.

PERROUX, F. O Conceito de Polo de Desenvolvimento. In: SPERIDIÃO, Faissol (Org). Urbanização e Regionalização: relações com desenvolvimento econômico Rio de Janeiro: IBGE, 1975.

PORTER, M. E. As vantagens competitivas. Rio de Janeiro: Campus, 1986.

PORTER, M. E. The competitive advantage of nations. New York: Free Press, 1990.

PORTER, M. E. Aglomerados e competição: novas agendas para empresas, governos e instituições. Rio de Janeiro: Campus, 1999.

SANTOS, Â. M. S. P. Economia, espaço e sociedade no Rio de Janeiro. Rio de Janeiro: FGV, 2003.

SCHUMPETER, J. A. The theory of economic development: an inquiry into profits, capital, credit, interest and business cycle. São Paulo: Abril, [1912] 1986.

SCOTT, A. J. Flexible production systems and regional development: the rise of new industrial spaces in North America and western Europe. International Journal of Urban and Regional Research, v. 12, n. 2, 1988.

SOUZA, N. de J. Desenvolvimento econômico. São Paulo: Atlas, 2007.

TIEBOUT, C. M. Exports and regional economic growth. Journal of Political Economy, v. 64, n. 2, p. 160-164, 1956. 
THÜNEN, J. H. V. The isolated state. New York: Pergamon Press, 1966.

WEBER, M. Theory of the Location of Industries. Chicago: University of Chicago Press, 1929.

\section{NOTAS DE AUTOR}

\section{CONTRIBUIÇÃO DE AUTORIA}

Anderson Miguel Knob - Concepção do manuscrito. Coleta de dados, Análise de dados, Elaboração do manuscrito.

Ivan Colangelo Salomão - Concepção do manuscrito. Participação ativa da discussão dos resultados; Revisão e aprovação da versão final do trabalho.

\section{FINANCIAMENTO}

Não se aplica.

\section{CONSENTIMENTO DE USO DE IMAGEM}

Não se aplica.

\section{APROVAÇÃO DE COMITÊ DE ÉTICA EM PESQUISA}

Não se aplica.

\section{CONFLITO DE INTERESSES}

Não se aplica.

\section{LICENÇA DE USO}

Este artigo está licenciado sob a Licença Creative Commons CC-BY. Com essa licença você pode compartilhar, adaptar, criar para qualquer fim, desde que atribua a autoria da obra.

\section{HISTÓRICO}

Recebido em: 10-03-2020

Aprovado em: 15-05-2020 